\title{
Current medical product development for diagnosis, surgical planning and treatment in the areas of Neurosurgery, Orthopeadic and Dental-Cranio-Maxillofacial surgery in Vietnam
}

\author{
L.C. Hieu ${ }^{1}$, L.H.Quoc ${ }^{2}$, V.V. Thanh ${ }^{3}$, T.D. Nguyen ${ }^{4}$, P.V. An ${ }^{5}$, L.T. Hung ${ }^{6}$, L. Khanh ${ }^{7}$ \\ ${ }^{1}$ Cardiff School of Engineering, Cardiff University, Wales, UK \\ ${ }^{2}$ Department of Science and Technology of Ho Chi Minh City, Vietnam \\ ${ }^{3}$ Ho Chi Minh City Hospital for Traumatology \& Orthopaedics, Vietnam \\ ${ }^{4}$ Department of Mechanical Engineering, Ho Chi Minh City University of Technology, Vietnam \\ ${ }^{5}$ National Centre for Technology Progress, Ministry of Science and Technology, Vietnam. \\ ${ }^{6}$ Department of Information Technology, Hanoi University of Technology, Vietnam \\ ${ }^{7}$ Departments of Medical Imaging and Neurosurgery, Central Army Hospital 108, Vietnam
}

\begin{abstract}
With the population of 86 million and good GDP growth in recent decades, the medical market in Vietnam is growing fast. However, most of the medical technology products are imported, and the number of locally manufactured ones is limited and they do not have the high competition capability in term of quality, quantity and types. In this paper, the current product development in Vietnam for diagnosis, surgical planning and treatment in the areas of Rehabilitation, Neurosurgery, Orthopeadic and Dental-Cranio-Maxillofacial surgery is presented. A roadmap for medical technology development in Vietnam is proposed.
\end{abstract}

Keywords: Product development, Neurosurgery, Orthopeadic, Dental-Cranio-Maxillofacial surgery

\section{INTRODUCTION}

With a population of 86 million and a steady GDP growth about $7 \%$ as shown in Fig. 1, the medical technology market in Vietnam is potentially huge. According to the Vietnam Ministry of Health (MOH), from 2005 to 2010, the government is projected to spend 1.8 billion USD for building 57 new hospitals [1]. From now until 2020, Ho Chi Minh City (HCMC) alone will spend 900 million USD to develop the municipal medical sector, mainly for building new clinics. Table 1 presents the health care expenditure in the ASEAN region. The healthcare expenditure per capita in Vietnam is still relatively low, but it is increasing very rapidly, from 21 USD in 2000 to 45 USD in 2006 [5]. The total health care expenditure of Vietnam is estimated to be 1.5 billion USD in 2010 [2].

Most of the medical devices and equipments in Vietnam, especially the ones related to advanced medical technologies, have to be imported. Currently, there are 15 local manufacturers that make 560 products officially licensed by the $\mathrm{MOH}$.

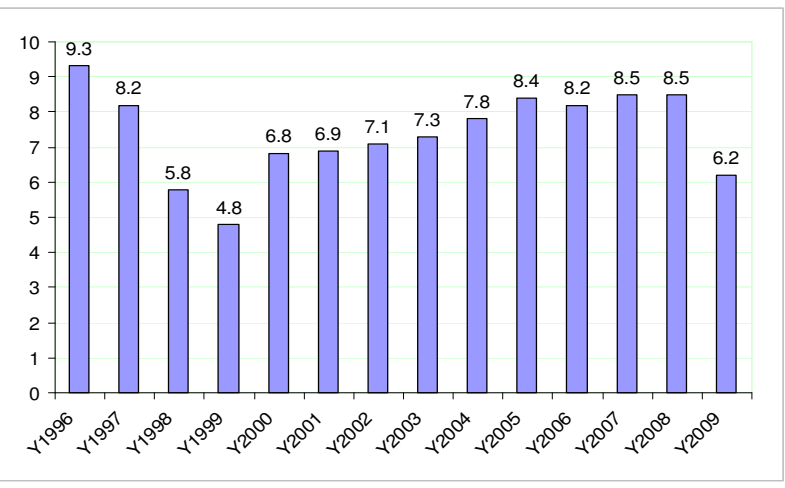

Fig.1 Gross Domestic Product (GDP) Growth - Vietnam (\%)

Table 1 Health care expenditure in the ASEAN region (Billion USD)

\begin{tabular}{|c|c|c|c|c|c|}
\hline & 2006 & 2007 & 2008 & 2009 & 2010 \\
\hline Indonesia & 6.2 & 6.4 & 6.7 & 7.0 & 7.4 \\
\hline Malaysia & 4.9 & 5.2 & 5.5 & 5.9 & 6.2 \\
\hline Philippines & 2.9 & 3.0 & 3.1 & 3.2 & 3.3 \\
\hline Singapore & 4.5 & 4.7 & 5.0 & 5.2 & 5.5 \\
\hline Thailand & 9.8 & 10.4 & 11.1 & 11.8 & 12.5 \\
\hline Vietnam & 1.2 & 1.2 & 1.3 & 1.4 & 1.5 \\
\hline Total & 29.5 & 30.9 & 32.7 & 34.5 & 36.4 \\
\hline
\end{tabular}

However, the local productions are limited to basic products, namely, plastic gloves, bandages, drips, compresses, clothes, masks, syringes and injection needles, sewing thread, surgery sutures, biomedical polymer membranes for burn therapy, lead rubber, barite powder and hospital furniture. The value of exports is low, at 81.8 million USD in 2007 , with $46.4 \%$ of medical products exported to Japan. 
The world market for medical technology is estimated to be 340 billion USD in 2009. It is growing steadily at an annual average rate of $4.5 \%$. The global orthopaedic market is estimated to have been worth approximately 40.6 billion USD in 2009. According to Research and Markets, in 2009, the Vietnamese market for medical equipment and supplies is estimated at 289 million USD, or 3 USD per capita [4]. It is expected that the medical device market in Vietnam will continue to expand at $5.9 \%$ per annum; this will take the Vietnamese market to 385 million USD in 2014, although the per capita rate will remain largely unchanged.

According to the US Commercial Service, $90 \%$ of medical supplies in Vietnam are imported [3]. An estimated $81.4 \%$ of the medical device market is supplied by imports [4]. Although the Vietnamese government established the targets to modernize the medical technology industry via the Decision 18/2005/QD-TTg issued on October $4^{\text {th }}, 2002$ about approving the national policy on medical equipments and devices for the 2002-2010 period, the current results are still very far from targets in which it is expected to meet 60 $\%$ of the medical sector's demands by 2010.

The Vietnamese medical market will rely on imports of high-end equipment in the coming years. Meanwhile, the human resources in the area of Biomedical Engineering (BME) are quite limited. Therefore, there is the emerging need for the realistic road map and effective work plans to develop BME technologies in Vietnam, especially in the areas of rehabilitation, neurosurgery, orthopedics, and dental-cranio-maxillofacial surgery.

\section{Current development}

A. Rehabilitation, neurosurgery, orthopedics, and dentalcranio-maxillofacial market in Vietnam

The huge need for medical technology products in Vietnam is clearly shown. According to Vietnam Orthopaedic Association, annually there are about 20,000 to 30,000 patients who need a hip and knee replacement. There are annually 20,000 surgeries conducted at HCMC Hospital for Traumatology and Orthopaedics. Every year, there are approximately 120,000 patients who need the surgery for treatment due to the traffic accidents. For each day in Vietnam, there are about 74 traffic accidents in which the estimated number of injured persons who have to be hospitalised is 84 [6].

There are an estimated 107,000 amputees living in Vietnam. Many lost their limbs in the Vietnam War and during subsequent border conflicts with neighboring China and Cambodia. Landmines and unexploded ordnances have continued to harm children and adults alike, decades after the wars ended. In recent years, work and traffic accidents, as well as disease and untreated infections, have taken the limbs of still more of Vietnamese people.

\section{B. Human resources development}

One of the objectives mentioned in the Decision 18/2005/QD-TTg of the Vietnamese government is to develop human resources specialised in medical technology development to ensure successful materialization of the principal contents of the national policy on medical equipment in the 2002-2010 period.

However, education and training in the area of Biomedical Engineering (BME) at universities in Vietnam were just started since 2003. In addition, most of these Biomedical Engineering programmes focus on medical electronics or bio-technology oriented subjects. High education training about medical product development, especially in the areas of design and manufacturing, biomechanics and biomaterials, is not available and limited at a few postgraduate researches.

\section{Biomaterial research and development}

Biomaterials are crucial for medical product development. There have been big efforts of institutes and universities working on R\&D of biomaterials in Vietnam since 1990s. Ministry of Science and Technology of Vietnam (MOST) funded the research project KC-DL-20-92 in 1992 which was aimed to produce stainless steels for medical applications. The project successfully produced the medical grade stainless steel, named K92, which has the similar quality compared to the imported products.

Since the beginning of 1990s, Niigrafit institute, Russia, produced carbon composite materials for medical applications under the commercial names Intost-1, Intost- 2 and Intost-3. The technology was transferred to National Centre for Technology Progress (Nacentech), MOST, and these biomaterial materials have been produced in Vietnam for medical applications since 1995.

The group at Hanoi University of Technology has developed the bioceramic materials, named Bioxitan, since 1996 with the financial support from MOST. The material was successfully applied for clinical cases under the project funded by MOH from 2003 to 2005.

The Institute of Chemistry, Vietnamese Academy of Science and Technology, successfully produced hydroxyapatite materials that are currently used for medical applications, including drugs for treatment of low bone density, and bone cements for orthopaedic and cranio-maxillofacial surgery.

In 2008, HCMC Institute of Physics was funded a research project to develop calcium phosphate, including hydroxyapatite and tricalicium phosphate, for medical applications. 


\section{Medical technology product development}

\section{a) Orthopeadic products}

Most of the orthopedic products such as plates, screws, nails, hip and knee implants as well as advanced surgical tools and devices have to be imported up to $98 \%$ in Vietnam. There are two R\&D groups in Vietnam actively working on development of these orthopedic products: (i) Central army hospital 108 (CAH108), and (ii) Nacentech.

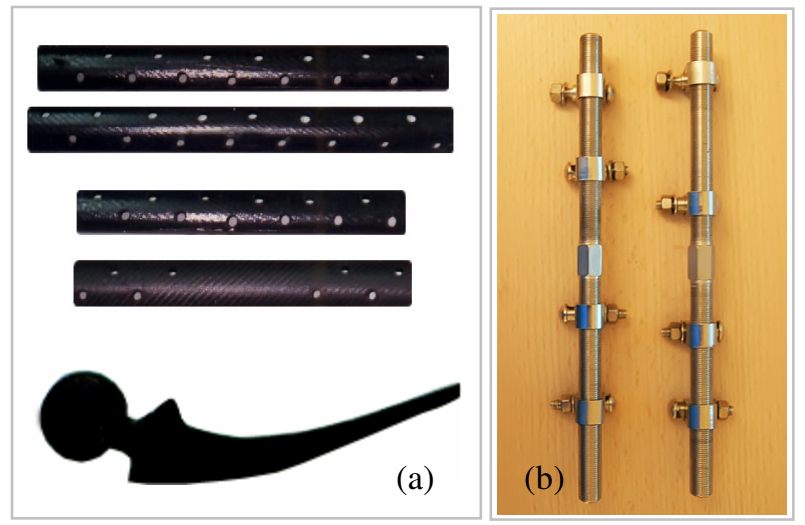

Fig.2 (a) Orthopaedic plates \& hip implant prototype made by Nacentech. (b) Orthopedic tools developed by CAH108.

The orthopedic products are made in Vietnam based on stainless steels and carbon composite materials which are locally produced. Figure 2 presents the typical orthopaedic plates, hip implant prototype and orthopaedic tools made by Nacentech and CAH108. There have been at least 4,000 plates produced by Nacentech for clinical applications.

Since 1993, the surgeons at Cho Ray hospital developed orthopaedic nails based on the design of Kuntscher nails; but did not success. However, surgeons at CAH108 successfully developed orthopaedic plates and tools based on the stainless steel produced in Vietnam since 2002. They also successfully conducted clinical cases using gamma nails for treatment of bone factures, and they are currently working on development of new gamma nails which are compatible with the size of anatomical structures of Vietnamese people.

In 2008, successful development of Steeffe plates was reported by CAH108 for treatment of the degenerative lumbar spondylolisthesis. The retro and postoperative study was carried out on 67 patients.

The current research in Vietnam in the area of medical product development for orthopedic surgery is to optimize the design and manufacturing processes as well as diversify the product types and applications.

\section{b) Dental cranio-maxillofacial products}

Since 1999, with the support of Belgian government and Catholic University of Leuven (K.U.Leuven), the medical technology project (MedTech) was developed and advanced medical technologies has been successfully transferred to partners in Vietnam, including Hanoi University of Technology, Nacentech, Cho Ray Hospital, HCMC University of Technology, CAH108. The project was also aimed to develop the BME human resources for Vietnam, especially in the areas of medical product development. Medical doctors, radiologists, researchers and lectures in Vietnam were selected to attend the short training course as well as join the R\&D research to develop BME products for Vietnam based on the local clinical need and resources.

Besides, HCMC University of Technology was funded the project KC 05-01 by Ministry of Science and Technology to invest Rapid Prototyping (RP) equipments for industrial and medical applications.

With the support of MedTech, there have been at least 50 clinical cases successfully conducted in Vietnam related to bone-reconstruction in which biomodels and personalised implants are used for surgical planning and treatment in the area of orthopeadic, dental and cranio-maxillofacial surgery [8,9]. Figure 3 presents the biomodels of the implant, bone structures and grafts for surgical planning and bone reconstruction treatment at CAH108.
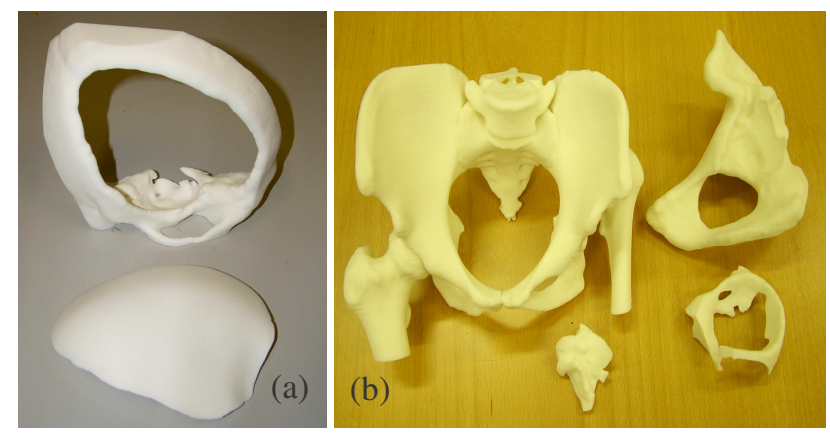

Fig.3 (a) Biomodel of the defect window and cranioplasty implant. (b) Biomodels of the hips \& bone grafts for surgical planning

Due to the high cost of personalised implants, Nacentech and MedTech successfully developed standard carbon composite templates from which cranioplasty implants are intraoperatively prepared for the surgery [6]. In this way, the cost of the implant is reduced to about 30 USD. Meanwhile, the cost for one personalised implant made of PMMA is from 300 to 350 USD. There have been at least 1,200 carbon composite templates produced by Nacentech for cranioplasty applications.

The bioceramic material, Bioxitan, developed by Hanoi University of Technology has been used for bone reconstruction since 2005. It is mostly used for reconstruction of the ear bones because of difficulty in making the complex parts from bioceramic materials. 
Finally, the other dental and cranio-maxillofacial products such as Ti sheets, plates and screws as well as the surgical tools and devices currently used in Vietnam have to be imported from other countries.

\section{c) Orthosis products}

Rehabilitation facilities in Vietnam are technically and financially supported from other countries, including Czech Republic, Germany and USA. Since 1990, Prosthetics Outreach Foundation [7] has transferred state of the art prosthetics design and manufacturing technology to Vietnam. Carbon composites produced by Nacentech have also been used for making the orthosis and prosthetics products. There have been 1,500 artificial legs made of carbon composite materials produced by Nacentech.

\section{ROADMAP FOR MEDICAL PRODUCT DEVELOPMENT}

Medical product development in Vietnam is still in the beginning steps and it is clear that Vietnam lacks both technology infrastructure as well as strong BME human resource. The continuous and sustainable development strategies, supports and investments from the government are urgently needed in order to reduce the cost and meet the big need of diagnosis and treatment in Vietnam.

In order to develop successfully the high value added products for medical applications in Vietnam, the authors proposed the following short, mid and long term plans:

1. Establishing Networks of Excellence (NoE) among the $\mathrm{R} \& \mathrm{D}$ research centres, institutes, universities and hospitals. These networks are aimed to build up and consolidate BME human resources, including oversea Vietnamese for medical product development in Vietnam.

2. Implementing $R \& D$ activities to meet the most emerging clinical needs based on the local resources, including the human, materials, design and manufacturing facilities. Besides, technology transfer activities need to be encouraged and invested from which human resources and expertise in the area of BME are developed.

3. Promoting the international collaborations about medical product development, especially with the countries in the ASEAN region.

4. Establishment of science and technology companies to commercialise R\&D results. The successfully developed products need to be diversified about the size, type and scope of applications as well as improve product quality with the long term support from the government.

\section{Conclusion}

The paper presents the current medical product development for diagnosis, surgical planning and treatment in the areas of rehabilitation, neurosurgery, orthopeadic and dental-cranio-maxillofacial surgery in Vietnam. Different aspects and R\&D activities related to medical technology as well as the market in Vietnam were presented. Finally the roadmap for medical product development in Vietnam was proposed.

With the good economic growth in recent decades, Vietnam presents the big market for medical technology products. However, most of the high value added products are imported, especially the ones related to advanced medical technologies. In addition, BME human resources development in Vietnam has just been fundamentally started in recent years. Although there are big efforts from the government as well as institutes, universities and hospitals working on medical technologies, the number of medical products successfully developed and commercialised is quite limited. In order to develop medical technology products to meet the emerging need of Vietnam, and have the capability to compete with the imported products, the effective collaborations as well as NoE should be established, and the government needs to develop the effective and realistic short, mid and long term R\&D programmes.

\section{REFERENCES}

1. The International Trade Administration, U.S. Department of Commerce at www.trade.gov

2. Espicom Business Intelligence at www.espicom.com

3. Asian Now: Navigating ASEAN region - Medical equipment and supplies, the US Commercial Service at www.trade.gov.

4. The Medical Device Market: Vietnam, Research and Markets at www.researchandmarkets.com.

5. National Health Accounts 2000-06, Ministry of Health of Vietnam.

6. Hieu L.C., Vander Sloten J., Bohez E., Phien H.N., Vatcharaporn E., An P.V., To N.C, Binh P.H. (2004). A cheap technical Solution for Cranioplasty treatments, Technology and Health Care, Vol.12. No.3, 281-292.

7. Prosthetics Outreach Foundation at www.pofsea.org

8. L.C.Hieu, J.Vander Sloten, E.Bohez, L.Khanh, P.H.Binh, Y.Toshev, N.Zlatov (2005). Medical Rapid Prototyping Applications and Methods, Assembly Automation Journal, Vol.25, No.4., 284-292.

9. Hieu L.C., Bohez E., Vander Sloten J., Phien H.N., Vatcharaporn E., Binh P.H., and Oris P. (2003). Design for Medical Rapid Prototyping of Cranioplasty Implants, Rapid Prototyping Journal, Vol.9, No.3, 175-186.

Author: Le Chi Hieu

Institute: Cardiff University

Street: Queen's Building, The Parade-Newport Road

City: Cardiff CF24 3AA

Country: UK

Email: Le-ChiH@cf.ac.uk 